Article

\title{
Tracking the Origin of Moisture over the Danube River Basin Using a Lagrangian Approach
}

\author{
Danica Ciric ${ }^{1, *}$, Milica Stojanovic ${ }^{1}$, Anita Drumond ${ }^{1}$, Raquel Nieto ${ }^{1,2}$ and Luis Gimeno ${ }^{1}$ \\ 1 Environmental Physics Laboratory (EPhysLab), Facultade de Ciencias, Universidad de Vigo, \\ Ourense 32004, Spain; smilica@alumnos.uvigo.es (M.S.); anitadru@uvigo.es (A.D.); \\ rnieto@uvigo.es (R.N.); 1.gimeno@uvigo.es (L.G.) \\ 2 Department of Atmospheric Sciences, Institute of Astronomy, Geophysics and Atmospheric Sciences, \\ University of São Paulo, São Paulo 05508-090, Brazil \\ * Correspondence: cdanica@alumnos.uvigo.es; Tel.: +34-988-387-208
}

Academic Editor: Anthony R. Lupo

Received: 16 November 2016; Accepted: 8 December 2016; Published: 14 December 2016

\begin{abstract}
In this study, we investigate the sources of moisture (and moisture for precipitation) over the Danube River Basin (DRB) by means of a Lagrangian approach using the FLEXPART V9.0 particle dispersion model together with ERA-Interim reanalysis data to track changes in atmospheric moisture over 10-day trajectories. This approach computes the budget of evaporation-minus-precipitation by calculating changes in specific humidity along forward and backward trajectories. We considered a time period of 34 years, from 1980 to 2014, which allowed for the identification of climatological sources and moisture transport towards the basin. Results show that the DRB mainly receives moisture from seven different oceanic, maritime, and terrestrial moisture source regions: North Atlantic Ocean, North Africa, the Mediterranean Sea, Black Sea, Caspian Sea, the Danube River Basin, and Central and Eastern Europe. The contribution of these sources varies by season. During winter (October-March) the main moisture source for the DRB is the Mediterranean Sea, while during summer (April-September) the dominant source of moisture is the DRB itself. Moisture from each source has a different contribution to precipitation in the DRB. Among the sources studied, results show that the moisture from the Mediterranean Sea provides the greatest contribution to precipitation in the basin in both seasons, extending to the whole basin for the winter, but being more confined to the western side during the summer. Moisture from the Caspian and Black Seas contributes to precipitation rather less.
\end{abstract}

Keywords: moisture sources and sinks; Lagrangian approach; precipitation; FLEXPART; Danube River Basin

\section{Introduction}

The global hydrological cycle is both an important element of the climate system and a decisive driver of water resources, which is why there is such intense interest in hydrology and meteorology for understanding the origin of moisture for precipitation over different regions of interest [1-3]. Europe is no exception, and many studies have shown a decreasing trend in precipitation over Central and Southern Europe, increasing over Northern Europe [4].

Rivers represent an important part of the global hydrological cycle, returning about $35 \%$ of continental precipitation to the oceans. Rivers also have a significant socio-economic role, in industrial activity, transportation, agriculture, and domestic fresh water supplies [5]. Because of climate change, the hydrological cycles of river basins vary over time, affecting their physical condition at regional scales [6]. The River Danube has a length of $2870 \mathrm{~km}$ and a catchment area of around $817,000 \mathrm{~km}^{2}$ (as shown in Figure 1), and is the second longest river in Europe. A total of 
19 countries (Germany, Austria, Slovakia, Hungary, Croatia, Serbia, Montenegro, Romania, Bulgaria, Moldova, Ukraine, Poland, Czech Republic, Switzerland, Italy, Slovenia, Bosnia-Herzegovina, Albania, Macedonia) constitute the Danube River Basin (DRB), making it the world's most international river basin [7]. Connected to 27 large and over 300 smaller tributaries (the DRB district), the river plays an important role in the ecological balance of the region, having a number of important socio-economic contributions as a waterway, a natural resource, and a source of energy [8].

The climate of the DRB is very diverse, with Atlantic influences in the western upper basin, and a Mediterranean influence in the southern part of the central and lower basin. Its proximity to the Mediterranean Sea means that the DRB receives high precipitation throughout the year [9].

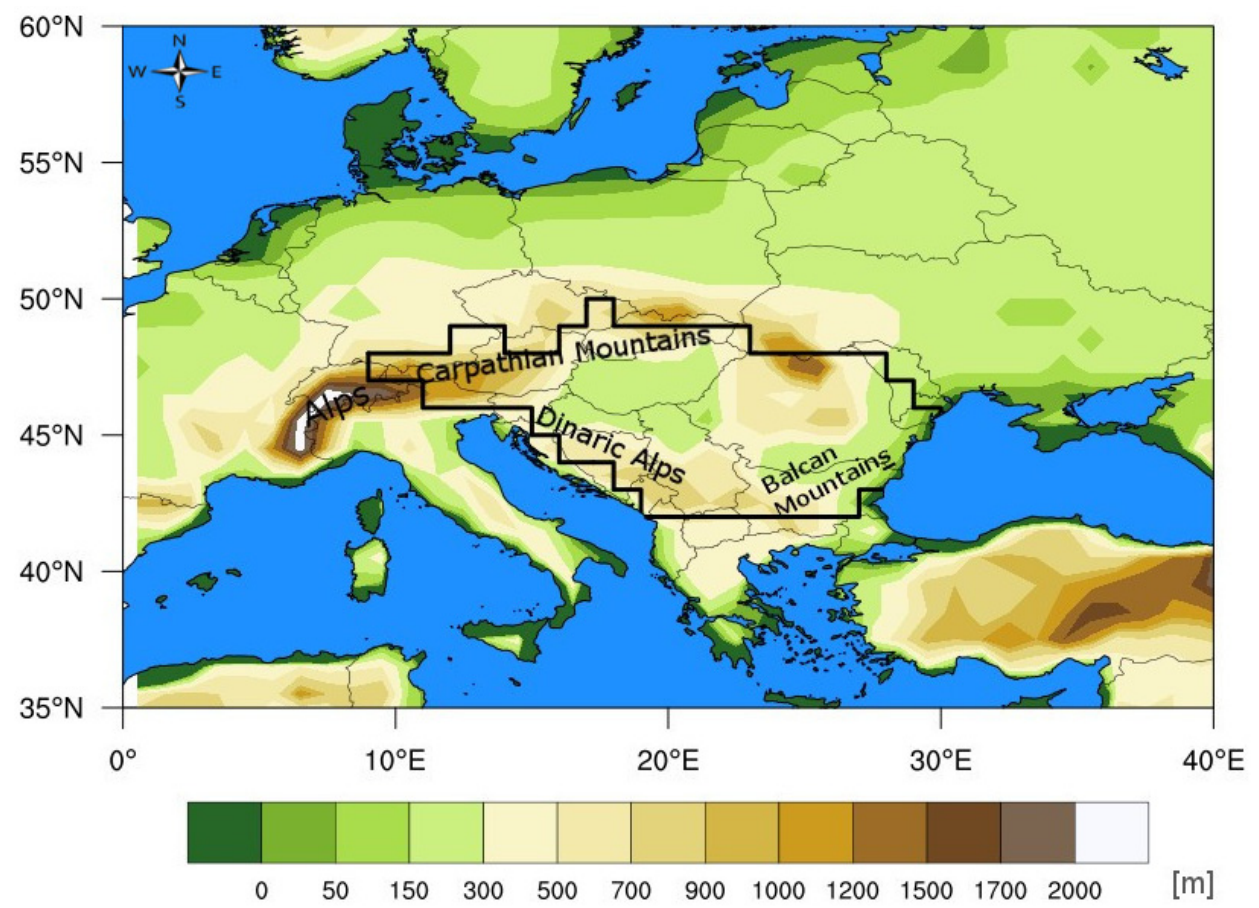

Figure 1. The black line indicates the Danube river basin. The colors are related to elevation (in meters).

River flow in the Danube is mainly a function of precipitation and evaporation in the Danube catchment. The mean annual rainfall throughout the catchment is strongly dependent on orography; one-third of the basin consists of mountains with the remainder being hills and plains. The total annual precipitation is estimated at about $2000 \mathrm{~mm}$ per year in the high parts (the Alps in the West, the Dinaric-Balkan mountain chains in the south, and the Carpathian Mountains in the north), about $500 \mathrm{~mm}$ per year in the plains, and less than $600 \mathrm{~mm}$ in the Danube delta. The annual mean evaporation is estimated at between 450 and $650 \mathrm{~mm}$ per year [8].

Many previous studies, using observational data in the DRB, have attempted to explain the effects of changes in precipitation and temperature on the flow regime, and on the possible changes in the natural drivers with impacts on water resources, water availability, extreme hydrological events, the quality of the water resources, and the ecosystem in the DRB [10].

It is very important to know the origin of the atmospheric moisture and the precipitation that occurs over a given region as they represent important elements of the atmospheric hydrological, so changes in the precipitation in one region may be dependent of changes in sources of moisture. The knowledge of the moisture sources is crucial to justify physically the changes in precipitation both for current and future climates [3].

Given the importance of the DRB in the moisture budget, the main objective of this paper is to track the origin of moisture for precipitation over the DRB. The identification of moisture sources can be accomplished by using a wide range of methods, which includes "analytical and box models", "physical water vapor tracers" (isotopes), and "numerical water vapor tracers". In the review by 
Gimeno et al. [3] a detailed review and comparison of the different approaches was done concluding that the Lagrangian approaches provide the more realistic source-sink relationships. In this paper, we have used the Lagrangian method developed by Stohl and James [11,12]. Using this method, Stohl and James studied the main flooding events and periods with intensive precipitation in central Europe, including the area around and within the DRB [11]. This approach has been extensively and successfully used in many regions throughout the world, including the Orinoco river basin [13], the Sahel [14], China [15], Iceland [16], Central America [17], the Mediterranean region [18], and the Sahelian Sudan region [19].

Specific objectives are (i) the identification of the major climatological source of moisture for the DRB for the 34-year period from 1980 to 2014 by tracking the air masses that ultimately reach the DRB backwards in time; (ii) to analyse the seasonal variability of these sources by comparing two seasons: the summer (April-September) and the winter (October-March); and (iii) to study the influences on the different moisture sources for precipitation at a subregional scale in the basin by tracking the air masses departing each source region and reaching the DRB forwards in time.

\section{Data and Methodology}

This study is based on the method developed by Stohl and James [11,12], which uses the Lagrangian particle dispersion model FLEXPART V9.0 [12] together with ERA-interim reanalysis data from the European Centre for Medium-Range Weather Forecasts (ECMWF) [20] at a $1^{\circ}$ horizontal resolution on 61 vertical levels from 0.1 to $1000 \mathrm{hPa}$. The analysis covers a 34-year period from October 1980 to September 2014. Our aim is to use this Lagrangian approach to determine the major moisture sources for the DRB, and the relative contributions of these to the precipitation.

The method has been widely used in a number of studies [13,21,22], and consists of dividing the atmosphere into a large number of air particles (approximately 2.0 million) with constant mass, which must take into account any changes in the density and volume of the air. The particles are transported using a 3-dimensional wind field. The transport time of the particles is limited to 10 days, this being the average period of residence of water vapor in the atmosphere [23]. The specific humidity $(q)$ and the position of all the particles are recorded at 6-h intervals. Changes in specific humidity $(q)$ with time $(e-p=m d q / d t)$, where $m$ is the mass of the particle, help us to identify those particles that lose moisture through precipitation $(p)$ or receive it through evaporation $(e)$ over each particle trajectory. By adding the $(e-p)$ of all the particles existing in the atmosphere over the area of interest, we obtain the total $(E-P)$ field, where $(E)$ indicates the evaporation rate and $(P)$ indicates the precipitation rate per unit area. The two main limitations of the method are (i) that we cannot calculate $E$ and $P$ separately and (ii) its reliability strongly depends on the quality of the input data. However, with such a large number of air particles it is hoped that any errors may cancel each other out given the number of particles contained in an atmospheric column [24].

Using the Lagrangian model FLEXPART we can identify the origins of the particles observed over the DRB via the backward analysis, which allows us to identify where the air masses gain humidity along their trajectories from their moisture source areas. Positive values of $(E-P)$ indicate those areas where evaporation dominates over precipitation. Through backward tracking, the particles over the target area (DRB) are returned to their source regions where they gain humidity, and using the annual averages of $(E-P)>0$ for the period 1980-2014 we can identify the source regions.

In order to identify the boundaries of the moisture source regions, we used the $90 \%$ percentile of the annual averages of $(E-P)>0$ for the backward experiment, which corresponds to a contour line of $0.06 \mathrm{~mm} /$ day. Although the definition of the threshold is arbitrary, this statistical procedure is valid and has successfully been applied in many previous studies using the same approach (e.g., [21]).

The Lagrangian forward experiment is used to identify where moisture is lost (precipitation exceeds evaporation) by the air masses that originate in each moisture source region, and reveals the moisture sinks. Negative values of $(E-P)$ indicate those areas where precipitation exceeds evaporation. A more detailed description of the use of backward and forward analysis to track moisture can be found in any of the many articles published in recent years describing this approach (e.g., Drumond et al. [24] for the Amazon Basin). 


\section{Results}

Due to the seasonality of the precipitation, the pattern of moisture sources is likely to vary over the year. The minimum potential evapotranspiration (PET) is in December and the maximum is in July, while for the annual cycle of precipitation (PRE) the minimum is in February and the maximum is in June as illustrated on Figure 2. To calculate PRE, PET, and the difference between them (P-E), we used the Climatic Research Unit (CRU) (TS3.23) [25] climate data set with a spatial resolution of 0.5 degrees. The annual cycle of P-E can help us to justify the definition of two annual seasons: a Winter season when P-E $>0$ (from October to March), and a Summer season when P-E < 0 (from April to September). The winter season encompasses the period October 1980 to March 2014, and the summer season refers to April 1981 to September 2014.

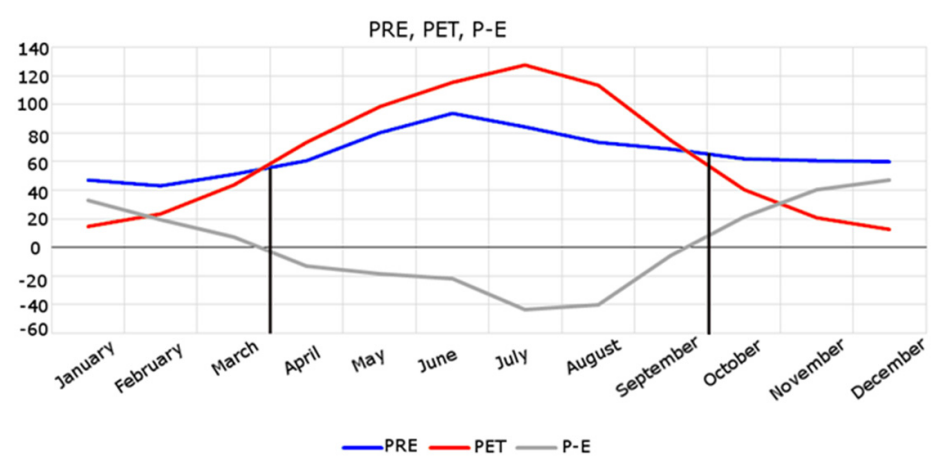

Figure 2. The climatological annual cycle of precipitation (PRE, blue line), potential evapotranspiration (PET, red line) and their difference (P-E, grey line) averaged over the Danube River Basin (DRB) for 1980-2014. Data from Climatic Research Unit (CRU). Scale in $\mathrm{mm} /$ day. Vertical red lines indicate the two identified seasons: summer from April to September and winter from October to March.

We tracked the air masses over the DRB backward in time to identify the sources. The areas characterised by the reddish colours represent regions where $(E-P)>0$, meaning that evaporation exceeds precipitation in the net moisture budget (moisture source), while areas characterised by the blueish colours represent regions where $(E-P)<0$, meaning that precipitation exceeds evaporation in the net moisture budget of the tracked air particles (moisture sinks). After identifying the sources of moisture over the DRB through backward analysis, forward analyses were applied to those particles leaving each source moving towards the target area (DRB) in order to estimate the contribution of each of these sources to moisture loss over the DRB. The annual values of 10-day integrated atmospheric moisture budget obtained via backward experiment from the DRB for the 34-year period October 1980-September 2014 are shown on Figure 3.

Moisture sources E-P for the Danube basin (1980-2014)

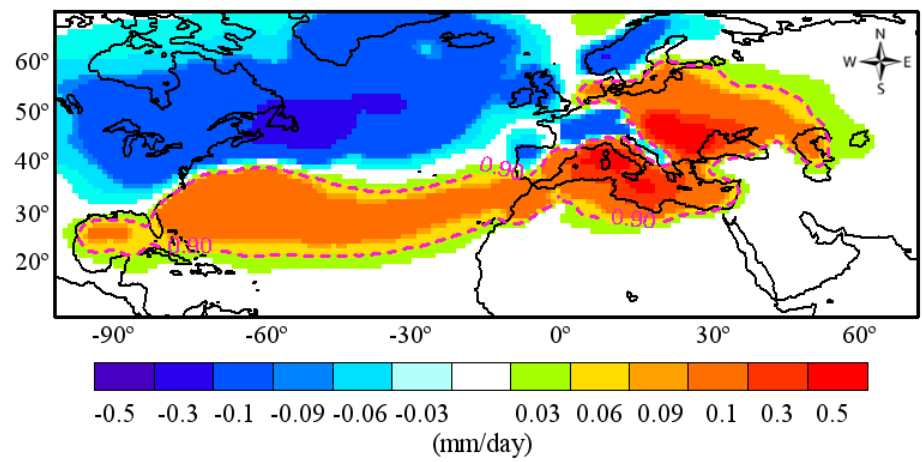

Figure 3. Climatological annual 10-day integrated $(E-P)$ obtained from the backward DRB experiment for the period October 1980 to September 2014. The pink dashed contour line delimits the source areas selected using the 90 th percentile of the $(E-P)>0$ values (i.e., $0.06 \mathrm{~mm} /$ day). 
According to the threshold of $0.06 \mathrm{~mm} /$ day, which corresponds to the $90 \%$ percentile of the annual averages of $(E-P)>0$ obtained from the backward experiment, and the methodology described above, the DRB mainly receives moisture from seven different oceanic, maritime, and terrestrial moisture source regions: North Atlantic Ocean (NATL), North Africa (NAF), Mediterranean Sea (MED), Black Sea (BS), Caspian Sea (CS), Danube River Basin (DRB), and Central and Eastern Europe (hereafter Rest of Land, RestL). These regions are shown in Figure 4.

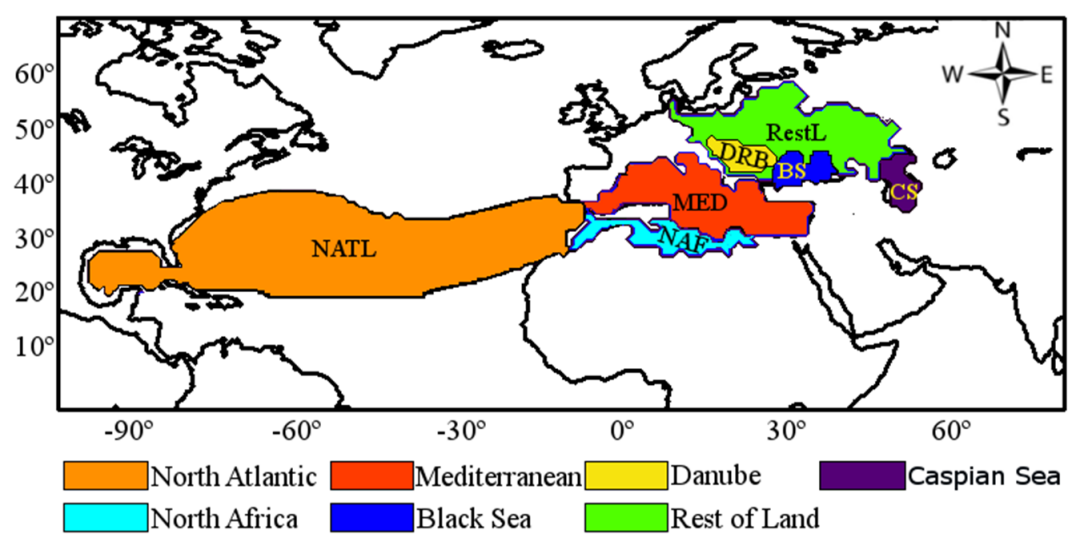

Figure 4. Schematic representation of moisture sources for the DRB identified in Figure 2.

The Lagrangian analysis of moisture sources at a seasonal scale (Figure $5 \mathrm{a}, \mathrm{c}$ ) shows that during the winter the dominant source of moisture for the DRB is the Mediterranean Sea, where the moisture uptake $(E-P>0)$ is greater than $0.3 \mathrm{~mm} /$ day, while during the summer the main source is the Danube basin itself where the moisture uptake exceeds $0.5 \mathrm{~mm} /$ day. The results show that $(E-P>0)$ over the North Atlantic is greater than $0.1 \mathrm{~mm} /$ day during the winter but less than $0.09 \mathrm{~mm} /$ day for the summer. The uptakes for the Rest of Land and the Black Sea are higher in the winter (approximately $0.3 \mathrm{~mm} /$ day) than in the summer, when they are insignificant. North Africa and the Caspian Sea are minor sources in both seasons.

Winter Season (OCT-MAR), 1980-2014

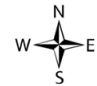

a) E-P Backward analysis

b) Climatology of VIMF

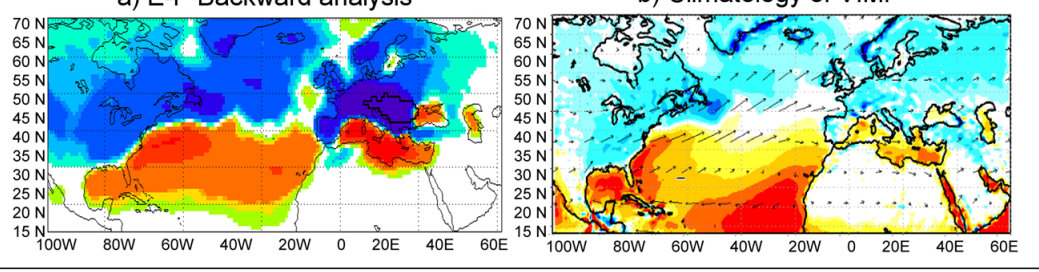

Summer Season (APR-SEP), 1980-2014

c) E-P Backward analysis

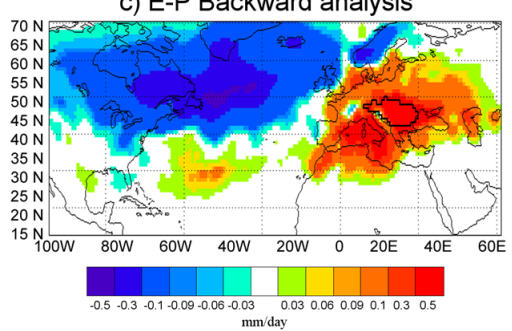

d) Climatology of VIMF

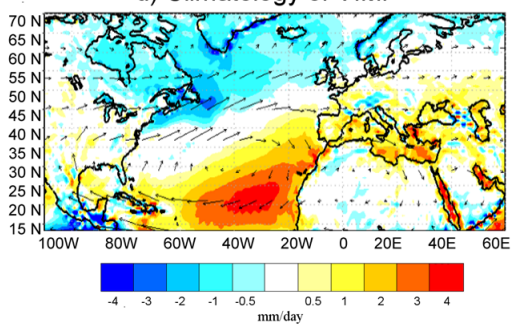

Figure 5. (a-d) Climatological seasonal values of 10-day integrated atmospheric moisture budget (E-P) obtained via backward trajectories from the DRB for (a) winter and (c) summer, and climatological seasonal vertically integrated moisture flux (vectors; in $\mathrm{kg} \cdot \mathrm{m}^{-1} \cdot \mathrm{s}^{-1}$ ) and its divergence (shaded; in $\mathrm{mm} /$ day) for (b) winter and (d) summer seasons. Data obtained from ERA-Interim. Thick black contour in (a) and (c) indicates the DRB. 
By comparison with the vertically integrated moisture flux (VIMF) (see Figure 5b,d), the most important regions of divergence (where evaporation exceeds precipitation) are over the Mediterranean Sea and the North Atlantic. The area of divergence over the North Atlantic is in accordance with the source moisture area during the winter (Figure 5b), with a moisture flux that originates in the North Atlantic and proceeds to the region of the Danube. In the summer (Figure 5d), when the North Atlantic source is weak, we note that the area of divergence over the North Atlantic is not as strong as in the winter, while over the Danube there is a small area of convergence.

The map of VIMF shows that the value of convergence (when precipitation exceeds evaporation) over the Danube exceeds $1 \mathrm{~mm} /$ day during the winter season, decreasing in size in summer and even showing a small region of divergence.

The contribution of each source of moisture for each of the 10 days of the backward analysis is shown in Figure 6, indicating the importance of each source along its trajectory for the period 1980-2014 (Figure 6a) and for two seasons: winter (October-March; Figure 6b) and summer (April-September; Figure $6 \mathrm{c}$ ). This contribution is calculated as the integral of evaporation-minus-precipitation over the ten-day back-trajectory. In these figures, the abscissa shows each of the 10 days for which the $E-P$ contribution of each source to the target region is calculated, and the ordinate shows the values of integrated $(E-P)_{1-10}$ for each of the seven sources in $\mathrm{mm} /$ day. Figure 6a (annual contribution) shows that RestL (Rest of Land), MED (Mediterranean Sea), and the Danube itself are the most important sources at the beginning of the ten-day period, while NATL (North Atlantic Ocean) is an important moisture source from the fourth day, becoming the most intense by day ten. The supply of moisture from BS (Black Sea), CS (Caspian Sea), and NAF (North Africa), although always positive, is lower than for the other regions. In the winter (October-March; Figure 6b), the Mediterranean Sea is clearly the most important source from the second day, and has a maximum contribution at day three. The North Atlantic begins to be an important moisture source from the third day and continues being so up to day ten. The Danube and RestL are not important sources on the first day of transport, but from the second day they start to contribute in a minor way to the supply. Although the Black Sea shows positive values throughout the ten days, its overall contribution is low. The most important contribution in summer (April-September; Figure 6c) is the Danube itself and the Rest of Land. The maximum contribution of these sources is seen on day one and they are significant up to the sixth day, after which their contribution diminishes somewhat.

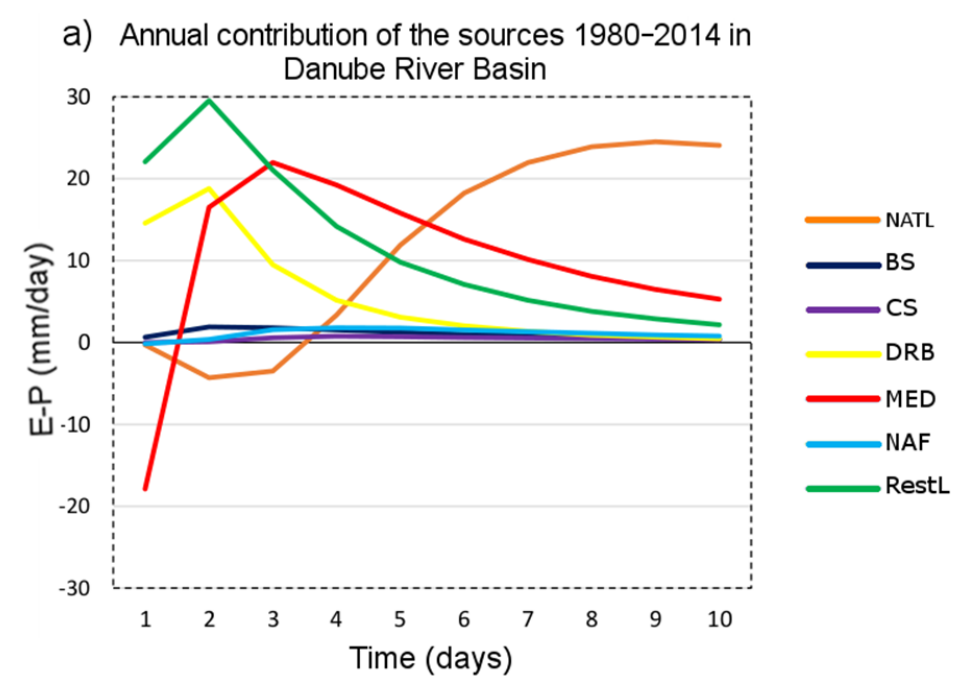

Figure 6. Cont. 
b) Contribution of the sources in the Winter season

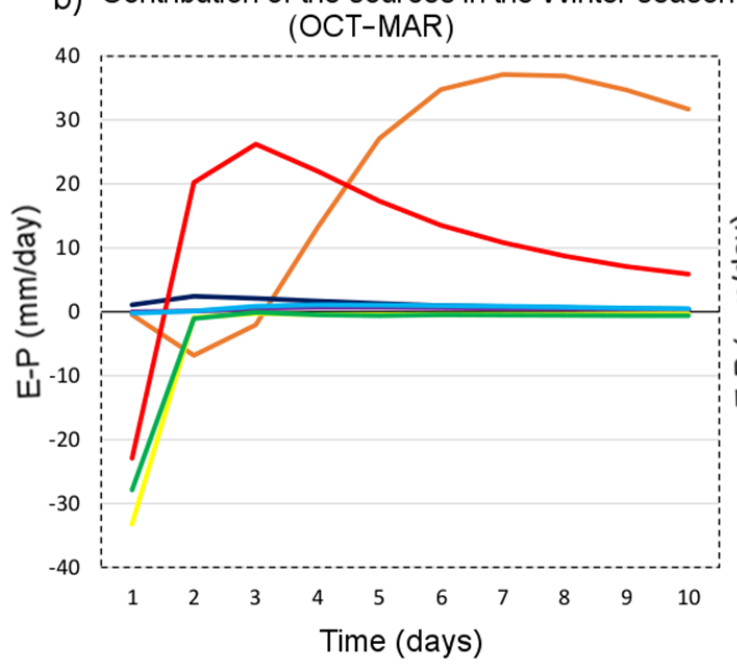

c) Contribution of the sources in the Summer season (APR-SEP)

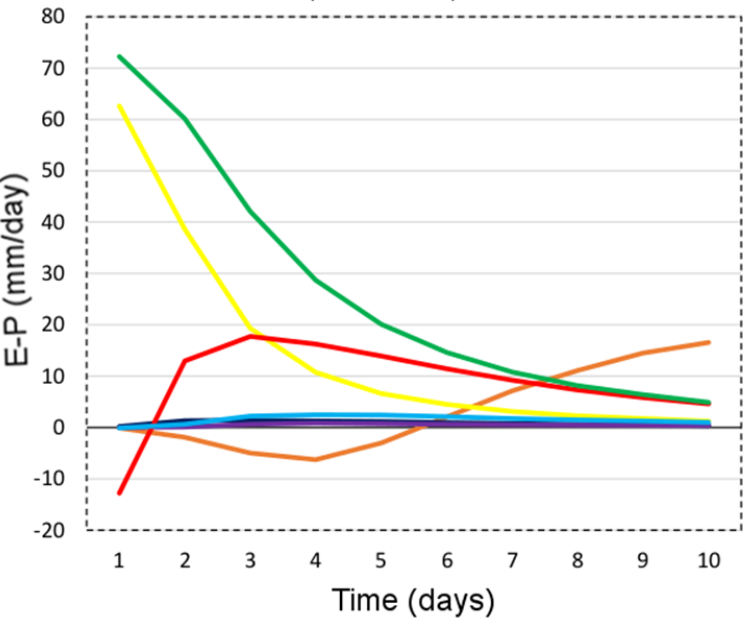

Figure 6. Absolute values of $(E-P)_{1-10}$ time series calculated backwards for the moisture over the DRB area and integrated over the regions of interest: NATL (North Atlantic Ocean) orange line, BS (Black Sea) dark blue line, CS (Caspian Sea) violet line, DRB (Danube River Basin) yellow line, MED (Mediterranean Sea) red line, NAF (North Africa) blue line, and RestL (Rest of Land) green line in $\mathrm{mm}$ /day. (a) Annual 10-day integrated E-P moisture contribution of the sources for the period 1980-2014. (b) 10-day integrated E-P moisture contribution for winter. (c) 10-day integrated E-P moisture contribution for the summer in $\mathrm{mm} /$ day.

The Mediterranean Sea is not a significant moisture source on the first day, but from the second day up to the end of the ten-days period it becomes much more significant. For the first six days the North Atlantic does not make any contribution to the target area, but from day six to day ten its contribution is on the increase. The Black Sea, Caspian Sea, and North Africa contribute throughout the ten-day period but the amounts are smaller.

The contribution of each source in percentage terms is shown in Figure 7. For each source we used the mean values for winter and summer for the whole of the period 1980-2014, and then for this period we calculated the average for each year. We used average values for each source for the whole period 1980-2014 to calculate the percentage contribution of each identified source. The percentage contribution for each source was obtained as the sum of all sources divided by the average value of each source, expressed in percentage terms. All seven sources have an influence on the DRB. From the Figure 7 it can be seen that in winter the Mediterranean Sea is the major source (31\%) followed by the Black Sea, the Danube, and the North Atlantic, and that there are three minor sources: North Africa, Rest of Land (Central and Eastern Europe), and the Caspian Sea. The contribution of the sources in the summer is rather different, with the DRB itself being the most important (51\%), followed by Rest of Land $(21 \%)$ and the Mediterranean Sea $(11 \%)$ as intermediate sources. The other sources contribute a much smaller percentage. 


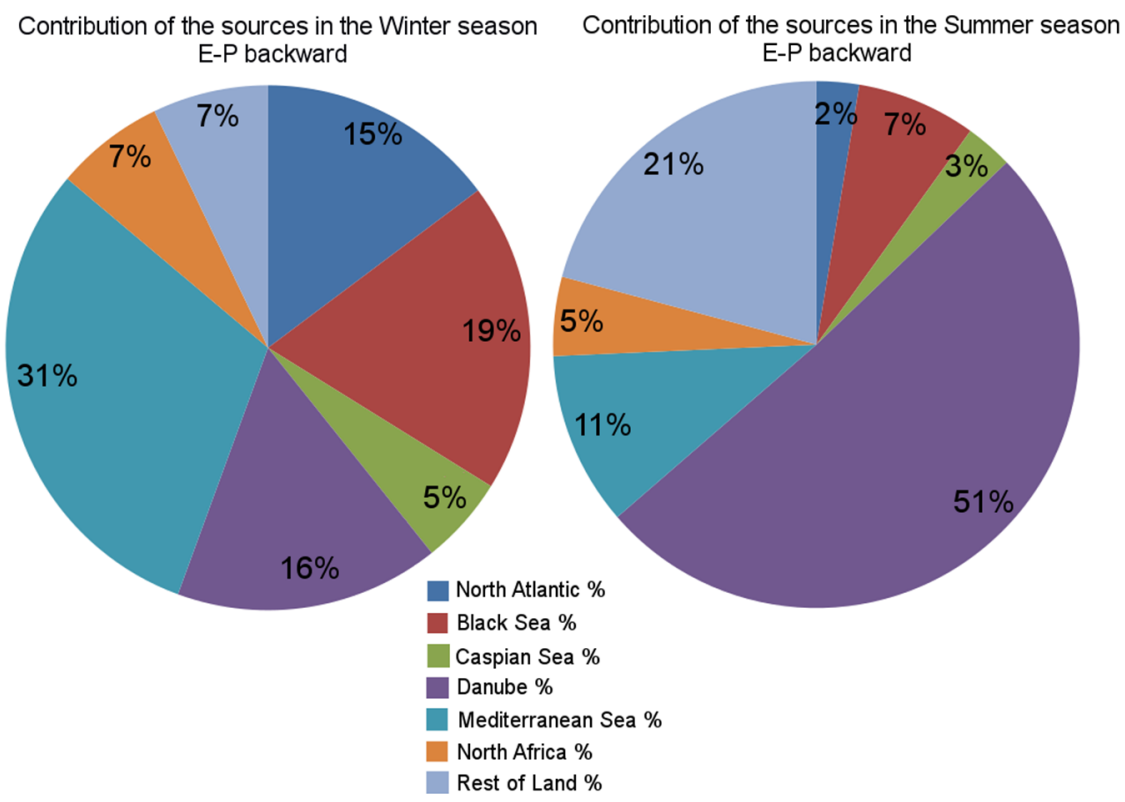

Figure 7. Moisture uptake over the sources obtained from $E-P$ backward analysis for the DRB for winter and summer in percentage terms $(\%)$.

The various moisture source regions considered can contribute in different ways to precipitation in different subregions inside the Danube basin, and this can also vary for both seasons. An estimate of the moisture provided by the air particles from each source region for precipitation in the basin can be achieved using forward trajectories over 10 days of $(E-P)$ for the 34-year period (Figure 8). The Lagrangian forward experiment identifies where moisture is lost (where precipitation exceeds evaporation) from the air masses from each moisture source region, enabling their moisture sinks to be identified. Because we are interested in precipitation, only negative values of $E$ - $P$ budget are displayed (the white areas of the maps represent regions where the (E-P) fields have low or positive values).

The contribution of the Atlantic Ocean to the target area differ between winter and summer. In winter, the Atlantic has a strong impact on the whole basin, its effects being most strongly felt in the southwestern subregion. During the summer, the spatial pattern is similar but the intensity is lower, and the Atlantic source has no impact at all in the southern part of the basin. The particles from the Black and Caspian Sea sources lose moisture over almost the whole basin during the winter, but the amounts are lower than for the Atlantic. The Black Sea loses more moisture than the Caspian Sea, especially in the center of the river basin. During the summer, these sources have a low impact in the basin area. In the central northern part of the basin, the greatest contribution is from the Danube source itself during the summer. Although the Mediterranean is the most significant source for the whole basin in both seasons, its influence is stronger in winter. During the summer, the maximum values are located over the northwestern and northern parts of the basin. Finally, the North African source has an impact over the whole of the target area in both winter and summer, but the amounts are low, while the Rest of Land contribution reaches the central and northern part of the basin during winter, but during summer it only reaches the western part of the DRB. 

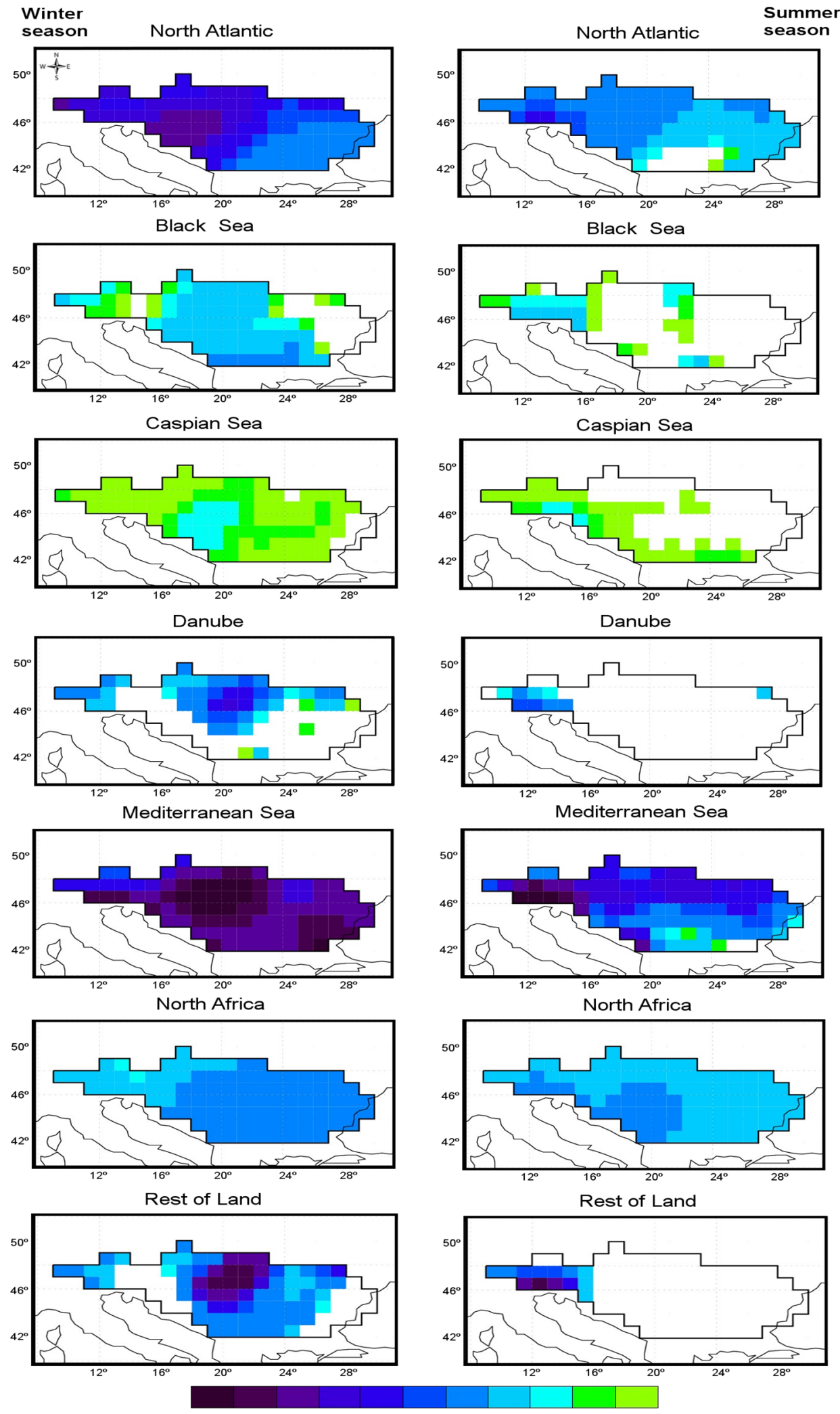

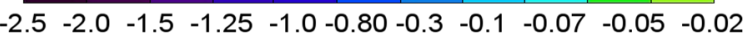

$\mathrm{mm} /$ day

Figure 8. Seasonal average values of $E-P<0$ for the period 1980-2014 determined from the forward Lagrangian experiment for: NATL, BS, CS, DRB, MED, NAF, and Rest of Land. The left-hand panels relate to the winter, while the right-hand panels relate to the summer months. Only negative values are shown to reflect sink regions. The thick black line delimits the DRB area. Scale is $\mathrm{mm} /$ day. 


\section{Discussion and Conclusions}

We used a Lagrangian approach based on the FLEXPART model to track water vapor in the atmosphere and to diagnose its sources and sinks for the DRB. In this approach we applied the method of Stohl and James [11,12] with the Era-Interim dataset [12].

The results show that the DRB mainly receives moisture from seven different oceanic, maritime, and terrestrial moisture source regions: North Atlantic Ocean, North Africa, Mediterranean Sea, Black Sea, Caspian Sea, Danube River Basin, and Rest of Land (Central and Eastern Europe). For each source, we calculated the percentage contribution of the total moisture supplied to the DRB. The contribution of these sources varies by season. During the winter (October-March), the main moisture source for the DRB is the Mediterranean Sea, while during the summer (April-September) the dominant source of moisture is the DRB itself.

Moisture from each source has a different contribution to precipitation in the Danube. Results show that the air particles from the Mediterranean Sea provide the greatest moisture losses in the basin in both seasons, extending to the whole of the basin for the winter, but being more confined to the western side during the summer. Moisture from the Caspian Sea and the Black Sea contributes the least to precipitation in the Danube basin in both seasons.

Our findings are in agreement with previous studies using this methodology to identify the moisture sources for different regions over Europe. Drumond et al. [26] analysed the main sources and sinks of moisture over the Mediterranean region in the period 1980-2000, showing the role of the Central Mediterranean Sea as the dominant moisture source for the Balkan Peninsula during the wet season, and Sodemann et al. [27] showed the major importance of the Mediterranean source for the moisture sources of the Southern Alps in a seven-year period analysis (from 1995 to 2002).

The DRB is a major source of moisture for itself during the summer, but this moisture does not contribute in any significant way to precipitation in the region overall.

Acknowledgments: D. Ciric and M. Stojanovic are supported by European Commission under the Erasmus Mundus project Green-Tech-WB: Smart and Green technologies for innovative and sustainable societies in Western Balkans (551984-EM-1-2014-1-ES-ERA Mundus-EMA2). R. Nieto acknowledges the support of the CNPq grant 314734/2014-7 by the Brazilian government. A. Drumond acknowledges funding by the Spanish Government and FEDER through the SETH (CGL2014-60849-JIN) project.

Author Contributions: R. Nieto, A. Drumond, and L. Gimeno conceived and designed the experiments; D. Ciric and M. Stojanovic performed the experiments and analysed the data; D. Ciric, M. Stojanovic, L. Gimeno, R. Nieto, and A. Drumond wrote the paper.

Conflicts of Interest: The authors declare no conflict of interest. The founding sponsors had no role in the design of the study; in the collection, analyses, or interpretation of data; in the writing of the manuscript, and in the decision to publish the results.

\begin{tabular}{|c|c|}
\hline \multicolumn{2}{|c|}{ Abbreviations } \\
\hline \multicolumn{2}{|c|}{ The following abbreviations are used in this manuscript: } \\
\hline BS & Black Sea \\
\hline CRU & Climatic Research Unit \\
\hline CS & Caspian Sea \\
\hline DRB & Danube River Basin \\
\hline E & Evaporation \\
\hline ERA & European Centre for Medium-Range Weather Forecasting Re-Analysis \\
\hline FLEXPART & FLEXible PARTicle dispersion model \\
\hline MED & Mediterranean Sea \\
\hline NAF & North Africa \\
\hline NATL & North Atlantic Ocean \\
\hline $\mathrm{P}$ & Precipitation \\
\hline PET & Potential evapotranspiration \\
\hline PRE & Precipitation \\
\hline
\end{tabular}




\section{References}

1. Christensen, J.H.; Christensen, O.B. Severe summertime flooding in Europe. Nature 2003, 421, $805-806$. [CrossRef] [PubMed]

2. Schär, C.; Vidale, P.L.; Lüthi, D.C.; Frei, C.; Häberli, C.; Liniger, M.A.; Appenzeller, C. The role of increasing temperature variability in European summer heatwaves. Nature 2004, 427, 332-336. [CrossRef] [PubMed]

3. Gimeno, L.; Stohl, A.; Trigo, R.M.; Dominguez, F.; Yoshimura, K.; Yu, L.; Drumond, A.; Duran-Quesada, A.M.; Nieto, R. Oceanic and terrestrial sources of continental precipitation. Rev. Geophys. 2012, 50, 1-41. [CrossRef]

4. Nikolova, N.; Vassilev, S. Variability of summer-time precipitation in Danube plain, Bulgaria. J. Geogr. Instit. Jovan Cvijic Serbian Acad. Sci. 2005, 54, 19-32. [CrossRef]

5. Gibson, J.J.; Aggarwal, P.; Hogan, J.; Herczeg, A. Isotope studies in large river basins: A new global research focus. EOS, Transactions. Eos Trans. Am. Geophys. Union 2002, 83, 613-617. [CrossRef]

6. Fan, J.; Huang, Q.; Cui, S.; Guo, A. Detecting runoff variation in Weihe River basin, China. Proc. Int. Assoc. Hydrol. Sci. 2015, 368, 233-238.

7. Lucarini, V.; Danihlik, R.; Kriegerova, I.; Speranza, A. Hydrological cycle in the Danube basin in present-day and XXII century simulations by IPCCAR4 global climate models. J. Geophys. Res. Atmos. 2008, 113. [CrossRef]

8. Rîmbu, N.; Boroneanţ, C.; Buţă, C.; Dima, M. Decadal variability of the Danube river flow in the lower basin and its relation with the North Atlantic Oscillation. Int. J. Climatol. 2002, 22, 1169-1179. [CrossRef]

9. The Danube Basin. Available online: http://www.danubebox.org/ (accessed on 8 June 2016).

10. Pistocchi, A.; Beck, H.; Bisselink, B.; Gelati, E.; Lavalle, C.; Feher, J. Water Scenarios for the Danube River Basin: Elements for the Assessment of the Danube Agriculture-Energy-Water Nexus; Publications Office of the European Union: Luxembourg, 2015. [CrossRef]

11. Stohl, A.; James, P. A Lagrangian analysis of the atmospheric branch of the global water cycle. Part I: Method description, validation, and demonstration for the August 2002 flooding in central Europe. J. Hydrometeorol. 2004, 5, 656-678. [CrossRef]

12. Stohl, A.; James, P. A Lagrangian analysis of the atmospheric branch of the global water cycle: Part II: Moisture transports between Earth's ocean basins and river catchments. J. Hydrometeorol. 2005, 6, 961-984. [CrossRef]

13. Nieto, R.; Gallego, D.; Trigo, R.M.; Ribera, P.; Gimeno, L. Dynamic identification of moisture sources in the Orinoco basin in equatorial South America. Hydrol. Sci. J. 2008, 53, 602-617. [CrossRef]

14. Nieto, R.; Gimeno, L.; Trigo, R.M. A Lagrangian identification of major sources of Sahel moisture. Geophys. Res. Lett. 2006, 33, L18707. [CrossRef]

15. Drumond, A.; Nieto, R.; Gimeno, L. Sources of moisture for China and their variations during drier and wetter conditions in 2000-2004: A Lagrangian approach. Clim. Res. 2012, 50, 215-225. [CrossRef]

16. Nieto, R.; Gimeno, L.; Gallego, D.; Trigo, R. Contributions to the moisture budget of air masses over Iceland. Meteorol. Z. 2007, 16, 37-44. [CrossRef]

17. Duran-Quesada, A.M.; Gimeno, L.; Amador, J.A.; Nieto, R. Moisture sources for Central America: Identification of moisture sources using a Lagrangian analysis technique. J. Geophys. Res. Atmos. 2010, 15, D05103. [CrossRef]

18. Nieto, R.; Gimeno, L.; Drumond, A.; Hernandez, E. A Lagrangian identification of the main moisture sources and sinks affecting the Mediterranean area. WSEAS Trans. Environ. Dev. 2010, 6, 365-374.

19. Salih, A.A.M.; Zhang, Q.; Tjernström, M. Lagrangian tracing of Sahelian Sudan moisture sources. J.Geophys. Res. Atmos. 2015, 20, 6793-6808. [CrossRef]

20. Dee, D.P.; Uppala, S.M.; Simmons, A.J.; Berrisford, P.; Poli, P.; Kobayashi, S.; Andrae, U.; Balmaseda, M.A.; Balsamo, G.; Bauer, P.; et al. The ERA-Interim reanalysis: Configuration and performance of the data assimilation system. Q. J. R. Meteorol. Soc. 2001, 137, 553-597. [CrossRef]

21. Drumond, A.; Nieto, R.; Gimeno, L.; Ambrizzi, T. A Lagrangian identification of major sources of moisture over Central Brazil and La Plata Basin. J. Geophys. Res. Atmos. 2008, 113, D14128. [CrossRef]

22. Gimeno, L.; Nieto, R.; Drumond, A.; Castillo, R.; Trigo, R. Influence of the intensification of the major oceanic moisture sources on continental precipitation. Geophys. Res. Lett. 2013, 40, 1-8. [CrossRef]

23. Numaguti, A. Origin and recycling processes of precipitating water over the Eurasian continent: Experiments using an atmospheric general circulation model. J. Geophys. Res. Atmos. 1999, 104, 1957-1972. [CrossRef] 
24. Drumond, A.; Marengo, J.; Ambrizzi, T.; Nieto, R.; Moreira, L.; Gimeno, L. The role of the Amazon Basin moisture in the atmospheric branch of the hydrological cycle: A Lagrangian analysis. Hydrol. Earth Syst. Sci. 2014, 18, 2577-2598. [CrossRef]

25. Harris, I.; Jones, P.D.; Osborn, T.J.; Lister, D.H. Updated high-resolution grids of monthly climatic observations-the CRU TS3.10 Dataset. Int. J. Climatol. 2014, 34, 623-642. [CrossRef]

26. Gómez-Hernández, M.; Drumond, A.; Gimeno, L.; Garcia-Herrera, R. Variability of moisture sources in the Mediterranean region during the period 1980-2000. Water Resour. Res. 2013, 49, 6781-6794. [CrossRef]

27. Sodemann, H.; Zubler, E. Seasonal and inter-annual variability of the moisture sources for Alpine precipitation during 1995-2002. Int. J. Climatol. 2010, 30, 947-961. [CrossRef]

(C) 2016 by the authors; licensee MDPI, Basel, Switzerland. This article is an open access article distributed under the terms and conditions of the Creative Commons Attribution (CC-BY) license (http://creativecommons.org/licenses/by/4.0/). 